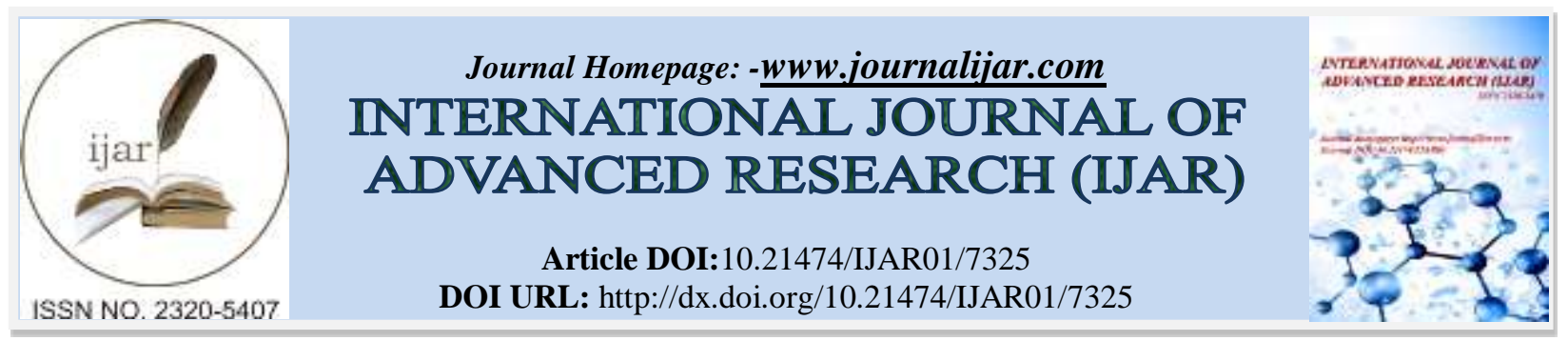

RESEARCH ARTICLE

\title{
A SURVEY STUDY FOR VITAMIN D DEFICIENCY IN HEALTHY FEMALES IN KARBALA CITY FROM $3^{\text {RD }}$ TO $6^{\text {TH }}$ DECADE.
}

Kasim Ali yousif.

Bsc. In chemistry, high diploma in Biochemistry.

\section{Manuscript Info}

Manuscript History

Received: 20 April 2018

Final Accepted: 22 May 2018

Published: June 2018

Keywords:-

vitamin D deficiency, females, Age.

\section{Abstract}

Background: Vitamin D, also known as the sunshine Vitamin, is produced by the body as a response to sun exposure, it can also be consumed in food or supplements ${ }^{(1)}$.

Vitamin D play's an important roles in maintaining healthy bones and teeth, support the health of the immune system, regulate insulin level and aid diabetes management and support lung function. The daily requirement of vitamin; D is 4000 I U, however; the National Institutes of Health (NIH) has suggested that vitamin D toxicity is unlikely at daily in take below 10,1000 IU/day.

The best day time of exposure to sunlight is from (10 am to $3 \mathrm{pm}){ }^{(2)}$.

Purpose : To study prevalences of vitamin D deficiency amony healthy adult females in Karbala city.

Subject: Two hundred healthy women aged more than 20 years old had been included in this study, whom were sampled from daily visitors of AL-Rasool medical lab during a period from March to April 2018 at Karbala city.

Method: Vitamin D assay had been evaluated by Cobas e 411 analyzer (Roch company).

Results: From 200 health females at a various age , 34 were within expected normal level of vitamin D (17\%), [26 optimal vitamin D, 6 upper normal and 2 excess but not toxic] and 166 were complains from vitamin D deficiency a different degree. (83\%) as suboptimal vitamin D provision 38 , slight to moderate 78 , and sever deficiency 41 and very sever deficiency were 9 .

Conclusions: vitamin D deficiency was common in healthy women in Karbala city, social condition that reflected in our life style which lead to cover most body surface from direct sun exposure, reduce daily sport in addition to regular popular known causes, like some times deficient vitamin D sources from diet.

Copy Right, IJAR, 2018,. All rights reserved.

\section{Introduction:-}

Metabolism:- vitamin D is derived from ergocalciferol (vitamin $\mathrm{D}_{2}$ ), obtained from plants in the diet, vitamin $\mathrm{D} 2$ is a 28 - carbon molecule derived from $\operatorname{ergoserol}^{(3)}$. 
Cholecalciferol (vitamin D3), formed in the skin by the action of ultraviolet light on 7- dehydrocholestrol. Vitamin D3 is a 27- carbon derived from cholestrol ${ }^{(3)}$.

The production of vitamin $\mathrm{D}$, in the skin is not an enzymetic process.

Vitamin D3 (cholecalciferol) is produced from 7- dehydrocholesterol by two step, UV light from the sun, the amount of UVB from sunlight varies according to season, rate of exposure to the sun and can also be obtained from the diet. The vitamin D in fish is D3, whereas that used for fortification is often D2 (ergocalciferol) . D2 is produced by UVB irradiation of ergosterol in plants ${ }^{(4)}$.

Three steps in metabolism of vitamin D ( 25- hydroxylation , $1-\alpha$ hydroxylation and 24- hydroxylation), all performed by cyto-chrome $\mathrm{P}_{450}$ mixed - function oxidases (CYPS) these enzyme are located either in the endo plasmic recticulum $\left(\mathrm{CYP}_{2} \mathrm{R}_{1}\right)$ or in the mitochondria $\left(\mathrm{CYP}_{27} \mathrm{~A}_{1}, \mathrm{CYP}_{27} \mathrm{~B}_{1}\right.$ and $\left.\mathrm{CYP}_{24} \mathrm{~A}_{1}\right){ }^{(5)}$

Importance:-Vitamin D plays an essential role in the regulation of metabolism, and absorption of calcium and phosphours for bone health ..

The presence of vitamin D receptor (VDR) in other tissue suggest that vitamin D physiology extends well above and beyond home- stasis ${ }^{(6)}$. Additionally the enzune responsible for conversion of $25-(\mathrm{OH}) \mathrm{D}$ to biologically active form (vitamin D) $1,25(\mathrm{OH}) 2 \mathrm{D}$ ) has been identified in tissues other than kidneys ${ }^{(7)}$.

Vitamin D is found naturally in only a few foods - Fatty fish (salmon ,tuna and mackerel), egg yolk, certain mush rooms - and in dairy product margarine, ready - to eat cereals, and fruit juices that have been fortified ${ }^{(8)}$.

Disease:- in low vitamin D state, the small intestine absorb approximately 10\% - 15\% of dietary calcium,but when adequate intestinal absorption of dietary calcium rises to approximately $30 \%-40 \%$. Hence low vitamin D levels may lead to insufficient calcium absorption and this has clinical implications not only for bone health but also for most metabolic function ${ }^{(9)}$. Vitamin D deficiency has reported for various disease as poor controlling of diabetes , osteoporosis and some type of cancer ${ }^{(10)}$.

Treatment:- vitamin D deficiency is treated by increasing dietary in take of food fortified with vitamin D or oral vitamin D treatment are available in several form (ample, tablet and gel capsule), dosages(200 to 500000 IU), and dosing (daily,weekly, monthly) ${ }^{(11) .}$

There are many established causes of vitamin D deficiency, as listed in Table 1.

Table 1:-majors causes of vitamin D deficiency

\begin{tabular}{|c|c|}
\hline Causes & Example \\
\hline $\begin{array}{l}\text { - Reduced skin synthesis } \\
\text { - Decreased absorption } \\
\text { - Increased sequestration } \\
\text { - Increased catabolism } \\
\text { - Decreased synthesis of 25- hydroxy vitamin } \\
\text { - D } \\
\text { - Increased Urinary loss of vitamin D }\end{array}$ & $\begin{array}{l}\text { - Sunscreen, skin pigment, season / time of day, } \\
\text { coeliac disease, crohn's disease. } \\
\text { - Gastric bypass, medications that reduce } \\
\text { cholesterol absorption } \\
\text { - Obesity (BMI > 30) } \\
\text { - Anti-convulsant, glucocorticoid } \\
\text { - Hepatic failure } \\
\text { - Nephrotic proteinuria }\end{array}$ \\
\hline
\end{tabular}

The established consensus of several vitamin D cut- off is presented in Table 2.

Table 2:-Diagnostic cut - off Levels of serum $25(\mathrm{OH}) \mathrm{D}^{(1)}$.

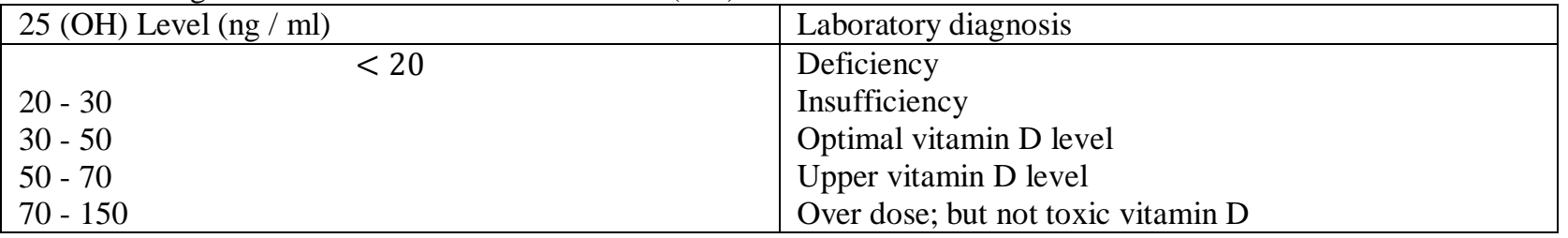




\begin{tabular}{l|l}
$>150$ & Intoxication
\end{tabular}

Blood levels of vitamin D are most commonly evaluated through measurement of serum (25-OH-D) while (1,25 $\mathrm{OH}-\mathrm{D})$ is active form of vitamin $\mathrm{D}$ it has a shorter half-life than (25-OH-D) (hours vs. weeks), thus , 25-OH-D is considered the best clinical indicator of vitamin D status ${ }^{(8)}$.

The effects of vitamin D are largely produced by the activated hormonal metabolite produced by a second stage hydroxylation from $25-\mathrm{OH}-\mathrm{D}$ by specific $1-\alpha$ hydroxylase making calcitriol $(1,25$ - dihydroxy vitamin $\mathrm{D})$, a process first identified in the kidneys and tightly regulated by parathyroid hormone ${ }^{(12)}$.

\section{Subjects, Materials and Method:-}

\section{Subjects Materials:-}

Women included in this study were selected according to age from 20-60 years old. Carefull history was taken from each woman regarding hypertension, diabetes mellitus, cancer and smoking. About 3 ml of venous blood aspirated into agel tube, waiting 20 minuts at room temperature for clotting, then centrifugation for 10 mints at 4000 RPM about $200 \mu \mathrm{l}$ of serum recovered in special cuvett for analysis.

\section{Method:-}

Vitamin D3 evaluate by Cobas e 411 analyzer which depend on (ECLIA) Electro-chemilumainescence binding assay. Competitive protein binding assay:

Principle: First, the sample is incubated with a pretreatment reagent for 9 minutes. Thereby, the naturell VDBP in the sample is denaturated to release the bound vitamin D $(25-\mathrm{OH})$. Second, the sample is further incubated with recombinant ruthenium- labeled VDBP to form a complex of vitamin D $(25-\mathrm{OH})$ and the ruthenylated - VDBP. Third, with the addition of biotinylated vitamin D (25-OH) a complex consisting of the ruthenium- labeled VDBP and the booting lated vitamin $\mathrm{D}(25-\mathrm{OH})$ is formed. The entire complex become, bond to the solid phase (by the interaction of biotin and streptavidin- coated microparticles which are captured on the surface of the electrode). Unbound substance are removed. Applying voltage the electrode induced chemiluminescent emission which is measured by a photomultiplier. Result are determined via instrument - specific calibration curve which is generated by 2 - point calibration and calibration master .

\section{Results:-}

200 healthy females were included in this study, Their serum vitamin D3 level were normals in 34 (17\%), while $166(83 \%)$ women were lower than normal value as (38 women suboptimal vitamin D, 78 women vitamin D deficiency , 41 severe vitamin D3 deficiency and 9 women very severe vitamin D3 deficiency) Table 3.

Table 3:-The prevalence of vitamin D deficiency \%

\begin{tabular}{|l|l|l|l|l|l|l|}
\hline Status & concentration & \multicolumn{2}{l|}{ Age (years) } & $\%$ \\
\cline { 3 - 6 } & & $20-29$ & $30-39$ & $40-49$ & $50-60$ \\
\hline $\begin{array}{l}\text { Very severe vitamin. D, } \\
\text { deficiency }\end{array}$ & $<5 \mathrm{mg} / \mathrm{ml}$ & 4 & 1 & 3 & 1 & 166 \\
$(83 \%)$ \\
\hline Severe vitamin D3 deficiency & $5-10$ & 13 & 5 & 11 & 12 \\
\hline Vitamin D3 deficiency vitamin; D3 & $10-20$ & 21 & 14 & 26 & 17 \\
\hline $\begin{array}{l}\text { Suboptimal } \\
\text { provision }\end{array}$ & 9 & 8 & 12 & 9 \\
\hline Optimal vitamin D3 level & $30-50$ & 9 & 6 & 8 & 3 & $34(17 \%)$ \\
\hline Upper normal & $50-7$ & 9 & 1 & 1 & 1 \\
\hline Over dose; but not Toxic & $70-50$ & 1 & - & 1 & - \\
\hline Vitamin D3 In toxic & $>150$ & & & & \\
\hline
\end{tabular}

To distribute our cases to age decades we divided them into group 1 (20 - 29 year), group 2 (30 - 39 year), group 3 (40 49 year), group 4 (50 - 59 year) as in Figure 1. 


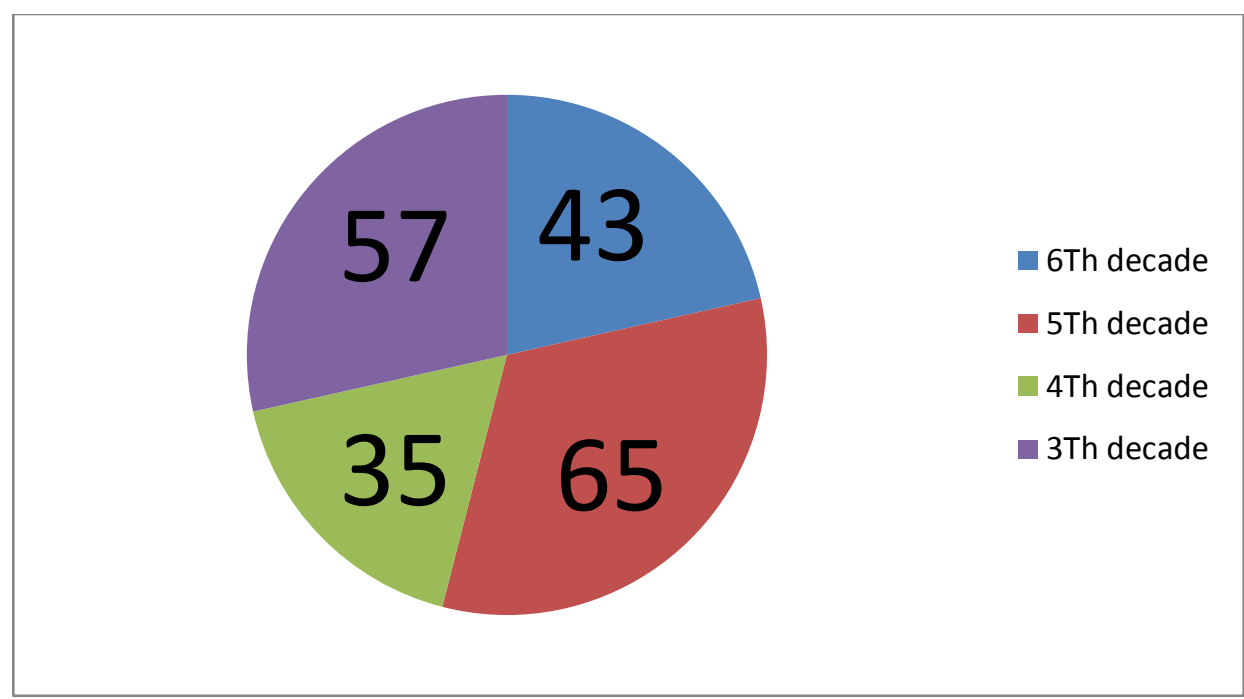

Figure 1:-Charts of cases distribution to age group

Then we studied their serum vitamin D3 level as in Table 4. which showed lower limit, upper limit of vitamin $\mathrm{D}_{3}$ and the mean value of vitamin $\mathrm{D}_{3}$ for each decade.

Table 4:-serum vitamin D3 assay distribution with age groups

\begin{tabular}{|l|l|l|l|l|l|l|}
\hline Age groups & $\mathrm{N}$ & Upper limit & Lower limit & Mean & Std.deviation & $\begin{array}{l}\text { Std.Error } \\
\text { mean }\end{array}$ \\
\hline 3Th & 57 & 81 & 3.1 & 17.7158 & 13.87259 & 1.83747 \\
\hline $4^{\text {Th }}$ & 35 & 69 & 3.8 & 21.1971 & 14.45951 & 2.44410 \\
\hline $5^{\text {Th }}$ & 65 & 83 & 3.1 & 21.0873 & 16.99669 & 2.10818 \\
\hline $6^{\text {Th }}$ & 43 & 56.3 & 3.9 & 15.1488 & 9.71252 & 1.48115 \\
\hline
\end{tabular}

The statistical correlation between serum vitamin $\mathrm{D}_{3}$ level with the our cases age group (in decade) was not significant at the ( P .value 0.05), as P. value of age group was more than P .values of the study, as in Table 5. And Figure 2.

Table 5:-statistically correlation of serum vitamin D3 with age groups (de- cades)

\begin{tabular}{|l|l|l|l|l|}
\hline \multirow{2}{*}{ Age group } & \multirow{2}{*}{ Mean Deference } & \multicolumn{2}{|l|}{$95 \%$ confidence interval of the difference } & \multirow{2}{*}{ P.value } \\
\cline { 3 - 4 } & & Lower & Upper & \\
\hline $3^{\text {Th }}$ & 17.7158 & 14.0349 & 21.3967 & 9.641 \\
\hline $4^{\text {Th }}$ & 21.1971 & 16.2301 & 26.1642 & 8.673 \\
\hline $5^{\text {Th }}$ & 21.0877 & 16.8761 & 25.2993 & 10.003 \\
\hline $6^{\text {Th }}$ & 15.1488 & 12.1598 & 18.1379 & 10.228 \\
\hline
\end{tabular}

Vitamin $\mathrm{D}_{3}$ leval 


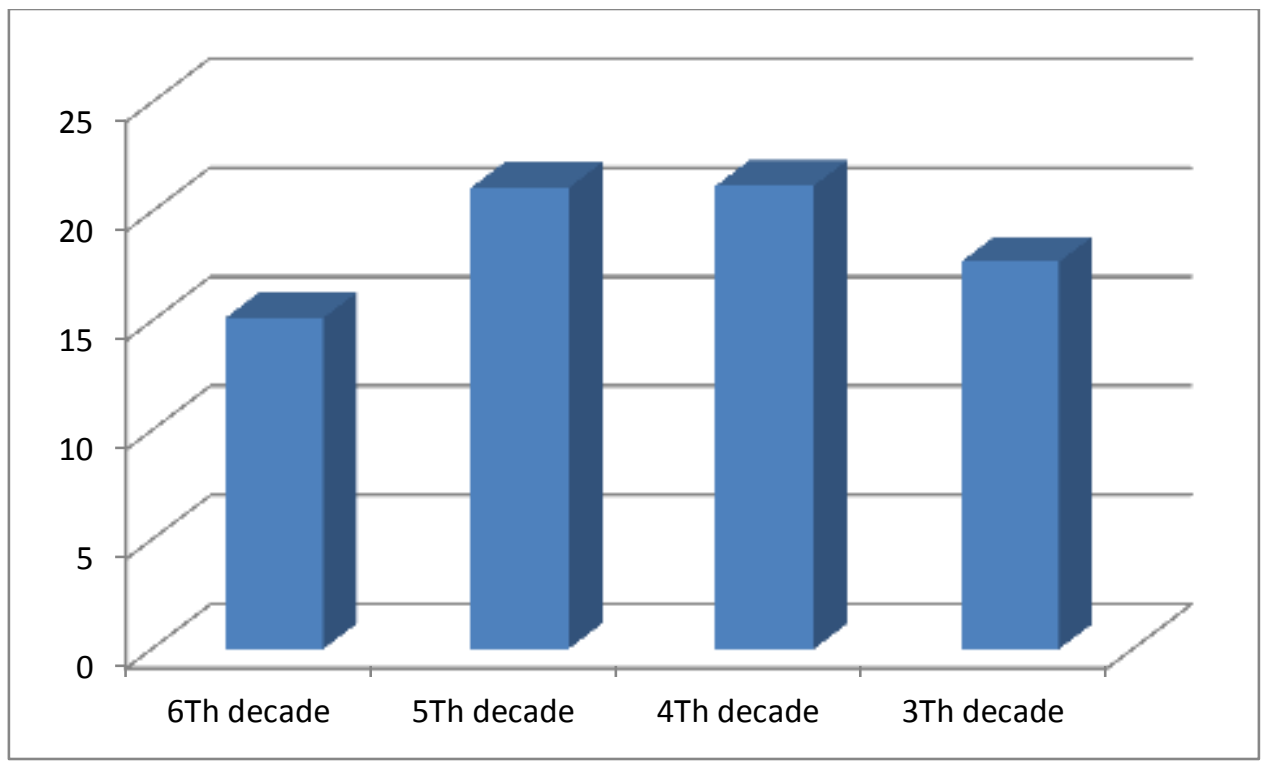

Figure 2:-Correlation of vitamin $\mathrm{D}_{3}$ with age group

\section{Discussion:-}

Vitamin D plays a vital role in variable physiological function in addition to its role in bone homeostasis . we complain from vitamin D3 deficiency in different age of male and females as due to variable causes as (non sun exposure using sunscreen, wearing a veil for cultural reason and more time spent in doors).

In our study which only healthy women aged between $3^{\text {rd }}$ to $6^{\text {th }}$ decade of life, there was $83 \%$ of our case complain from low vitamin D3 level while $17 \%$ of our cases had normal vitamin D3.

In Qatar, $97 \%$ of all health care professional were vitamin D3 deficiency (mean level <30 ng/ml) ${ }^{(13) .}$

Vitamin D3 deficiency has become a global public health problem . several studies have focus on the prevalence of vitamin D3 deficiency world wide.

Some European countries showed moderate risk of deficiency, where vitamin D3 $<20 \mathrm{ng} / \mathrm{ml}$. Was found $5 \%$ in Ireland , 50\% in Germany and approximately $40 \%$ in Spain ${ }^{(13)}$. Because of the amount of skin exposer to the sun such as your back (rather than a small area such as our face or hands), sport exercise and the clothing style.

From these $83 \%$ of vitamin D3 deficiency lower than $30 \mathrm{ng} / \mathrm{ml}$, 38 (19\%) suboptimal vitamin $\mathrm{D}_{3}$ provision. While there was difference with other study from Tunisia reported a lows prevalence of vitamin $\mathrm{D}_{3}$ deficiency in $47 \%$. Others factor that may drive these differences include inadequate vitamin D.

Fortification in dietary products (milk, cereal, and drinks such as orange juice), and difference In clothing style.

There was no statistical correlate age group and mean group of vitamin D, because the mean of serum vitamin D3 were nearby each to other show in Table 5. and Figure 2.

The correlation between vitamin $\mathrm{D}_{3}$ level with age group (in decades) was not significant ( $\mathrm{P}$. value 0.05 )

\section{Statistical analyzes:-}

Our Data were studied statistically by Excel 2013, T test using (SPSS 22 system).

\section{Conclusion:-}

Regardless of age, vitamin D3 deficiency status seems to be an important issue facing the world today. 
In our study, the correlation between serum vitamin D3 level with our cases age group was not significant, because the mean of serum vitamin D3 were nearby each to other, and the prevalence of vitamin D3 deficiency in our study multifaceted, where lack of sunlight exposure and inadequate diet.

\section{Recommendations:-}

Our study recommended to get proper sun exposure daily for 15 minute , 3-4 times weekly.

Take adequate health diet riches with vitamin D3, as well as vitamin D3 available in fortified food such as milk, cereals and to regular serum vitamin D3 evaluation and take medication as need or a doctor.

\section{References:-}

1. Alshahrain F ,Aljohani N. vitamin D: deficiency, sufficiency and toxicity , Nutrient 2013 ; 5: (3605-3610)

2. Song H R, kweon S S , choi J S , Rhee J A, lee Y H , Nam H S , jeong S K , park K S , Ryu S Y, choi S W, and Shin M H : High prevalence of vitamin D deficiency in adults aged 50 year and older in Gwangju, Korea: the Dong- gu study. JKMS 2014, 29:(149-151).

3. Crook M A. Calcium, phosphate and magnesium in : coork M A, clinical biochemistry and metabolic $.8^{\text {th }}$ edition india 2010: Taylor and Franci group, LLC: (97-98)

4. Bikle D D: vitamin D metabolic, mechanism of action, and clinical application . National institutes of health 2014: 20; $21(3): 2$

5. Christakos S, Ajibade D V,Dhawan D, Fechner A J,and Mady L S. vitamin D: metabolism . National institutes of health 2010;39(2)2.

6. Bellan M, Guzzaloni G, Rinaldi M, merlott E, Ferrai C, Tagliaferri, A, Pirisi M, Aimaretti G, Scacchi M, and Marzullo p. altered glucose metabolism rather than naive type 2 diabetes mellitus (T2 DM) is related to vitamin D status in sever obesity . cardiovascular diabetology 2014;13:(2-10)

7. Gallagher C. vitamin D Aging . National institutes of health $2013 ; 42$ (2): (1-4).

8. Rockwell M , kraak v, Hulver $\mathrm{M}$ and Epling J: clinical (mana-gement of low vitamin D: ascoping review of physicians practices. Nutrient 2018, 10 (1-2).

9. Zilva J F . calcium, phosphate and magnesium metabolism . zilva JF , chinical chemistry in diagnosis and treatment. $5^{\text {th }}$ edition singapor 1988: (177-179).

10. Nasri H, Ardalan M-R. Association of serum vitamin D level with age in idividuals with normal renal function.Journal of nephropharmacology 2012;1(1):8

11. LeBlance E S, Zakher B, Daeges M, pappas M, and Chou R. Screening for vitamins D deficiency : A systematic review for the U.S.preventive services task force. Annals of internal medicine $2015 ; 162$ (2): 109

12. Boucher B J . The problems of vitamin D insufficiency in older people . Aging and disease $2012 ; 4: 314$

13. AL-Mogble E S, vitamin D status among a dult Saudia females visiting primary health care clinics . international journal of health sciences $2012 ; 6(2): 99-105$ 